\title{
The legacy of Queensland Aboriginal Creations and contemporary artefact production
}

\author{
Gretchen Stolte
}

\begin{abstract}
Queensland Aboriginal Creations, or QAC, was the marketing arm for Queensland's Department of Native Affairs, officially launched in 1959 and continuing until 1995. The decades in between are fascinating studies of material culture production, government policy intervention, First Nation agency and innovation and, ultimately, the continuation of cultural traditions and knowledges that span tens of thousands of years. The Department of Native Affairs had production centres across the state, mass producing boomerangs, bark paintings and pottery. In August 2019, I was contracted to curate the exhibition based on almost 10 years of 'living with' the QAC story and all its multifaceted aspects. This article explores the policies and production systems of Queensland Aboriginal Creations and how those systems influence and affect artists today through the lens of the University of Queensland's Anthropology Museum's exhibition Agency and Legacy. A brief overview of the scope of QAC's activities will provide the overall context but it is especially through the production of artefacts and boomerangs that the innovative spirit of artists arises and the real legacy of those policies becomes apparent. Specifically, this article shifts the conversations around boomerangs from a tourist curio to a work of cultural importance through the lens of Agency and Legacy and in conversation with contemporary makers.
\end{abstract}




\section{Introduction}

In February 2020, the University of Queensland's Anthropology Museum (UQ Anthropology Museum) launched Queensland Aboriginal Creations: Agency and Legacy to a packed room. Out of almost 3,000 objects in various collections, over 150 works were chosen to be displayed. The exhibition spans the expected (bark paintings, pottery and boomerangs) to the less expected (netted baskets, strung shells and fine wood carvings). Additionally, over 200 historical photographs from private family collections telling the personal story of the curio shop were carefully crafted into a slide show presentation, ${ }^{1}$ while photographs and stories from the State Archives contextualised the histories behind many of the objects. The full range of the curio shop that was Queensland Aboriginal Creations was on show for everyone to see and the ownership of that story was shared by all in attendance at the opening. The event was described by many as one of 'coming home', but this home has long been misunderstood.

Agency and Legacy is where the historical and the contemporary sit side by side with both fond nostalgia and uncomfortable tension. Queensland Aboriginal Creations or QAC was the marketing arm for Queensland's Department of Native Affairs, officially launched in 1959 and continuing until 1995. The decades in between are a fascinating study of material culture production, intense government policy intervention, First Nation agency and innovation, and, ultimately, the continuation of cultural traditions and knowledges that span tens of thousands of years. The Department of Native Affairs, through QAC, had production centres across the state, mass producing boomerangs, bark paintings and pottery. Missions and early stage art centres sent spears, woomeras (spear throwers), coolamons, shell necklaces, natural fibre woven bags and other artefacts to the curio shop in Brisbane for sale. QAC also facilitated some of the most notorious breaches of cultural copyright to arguably ever be sanctioned in Australia. These examples of copying often overshadow the other activities QAC facilitated, making anything connected with QAC heavily tainted as either tourist tat or unauthentic or both. The lack of understanding of this history has a direct effect on artists producing today and knowing the QAC story alleviates many misconceptions. More importantly, knowing the history of artefact production in Queensland shifts the understanding of cultural artefacts away from a tourist commodity and makes space for the appreciation of these works as fascinating and significant cultural pieces. $^{2}$

\footnotetext{
1 Credit for this portion of the exhibition goes to Curatorial Officer Mandana Mapar who put together the photographs, working closely with families and artists.

2 For a detailed historical account of QAC's development and programs from the late 1800s through to the 1980s, see Chapter 2 'Curios and Artefacts' in Stolte, Aboriginal and Torres Strait Islander Art, 19-55.
} 
This article explores the policies and production systems of Queensland Aboriginal Creations and how those systems influence and affect artists today through the lens of the UQ Anthropology Museum's exhibition Agency and Legacy. A brief overview of the scope of QAC's activities will provide the overall context but it is especially through the production of artefacts and boomerangs that the innovative spirit of artists arises and the real legacy of those policies becomes apparent. For example, boomerangs are often an undervalued and under-appreciated form of artistic expression and, because of this, artists employing the medium today to convey their own deep cultural meanings and significances are often overlooked or regulated into commercial commodities. This article reimagines boomerangs away from a tourist curio to a work of cultural importance through a summary examination of QAC's policies and activities while in conversation with contemporary makers. ${ }^{3}$

\section{Queensland Aboriginal Creations}

The history of artefact and art production in Queensland differs from other areas of Australia. This history is due in large part to the policies enacted by the Department of Native Affairs and their heavy involvement in artefact production. Artefact production in Queensland has been in continuous practice since well before the arrival of the Europeans but colonial processes had a huge hand in redirecting the reception and even the crafting of those objects. From the late 1800s to the early 1900s, Torres Strait Islanders and Aboriginal communities across Queensland produced material culture objects for sale and collection by museum collectors and salvage anthropologists. ${ }^{4}$ From the early 1930 s, public requests for artefacts began to boom. Research into the State Archives reveals the nature of some of these requests and their far-ranging scope. Requests for artefacts and artworks, but especially boomerangs, were both domestic and international, including Germany, France, Italy, the United States, Canada, Mexico and Japan. ${ }^{5}$

There was a growing market for boomerangs while, at the same time, there was the persistent government desire to 'solve the Aboriginal problem' by creating economic opportunities. Beginning in the 1930s, the government began to encourage the production of artefacts as a source of economic viability. Queensland was not alone in this approach of linking cultural arts to commercial markets and the creation of these markets sits amid a broader trend in world Indigenous affairs. Prime examples of these

\footnotetext{
3 Specifically, this article looks at the cross-cultural engagements between First Nation peoples and nonIndigenous collectors. It should be noted that production and exchange between Aboriginal and Torres Strait Islander people needs to be given its own treatment.

4 See Allen, 'A History of Collecting Indigenous Artefacts in North Queensland'; Allen, 'Tons and Tons of Valuable Material'; Jones, 'The "Idea Behind the Artefact"'; and Perusco, 'Only Sticks and Bark'.

5 Queensland State Archives (QSA) Item ID336666 and Item ID336929, summary of multiple letters of correspondence across both files. See particularly a letter from the Mexican Consul for 'certain Australian novelties suitable for gift purposes' dated 5 April 1939. Cited in Stolte, Aboriginal and Torres Strait Islander Art, 23.
} 
efforts are programs developed in the 1930s in Canada and the United States for the production of cultural material by the Inuit and Pueblo communities, respectively. ${ }^{6}$ 'Cultural arts' were seen as the 'solution' to the 'Indian problem' in North America ${ }^{7}$ and it becomes apparent in the archive that the same philosophy was used in Queensland.

In the early months of 1933, the Chief Protector of Aborigines J. W. Bleakley began coordinating with Aboriginal and Islander communities along with the Government Tourist Bureau to develop displays of Aboriginal and Islander curios. These displays were usually available during the tourist season and were made up of 'marine curios and aboriginal [sic] works of art'. ${ }^{8}$ On 19 December 1933, a memorandum from Bleakley to the Protector on Thursday Island reflects on the first window display as a way of 'ascertaining whether there was any demand' for such items by the general public. ${ }^{9}$ Displays continued for several decades not only as a way of showcasing Aboriginal and Islander creativity and ingenuity but also to incite public interest.

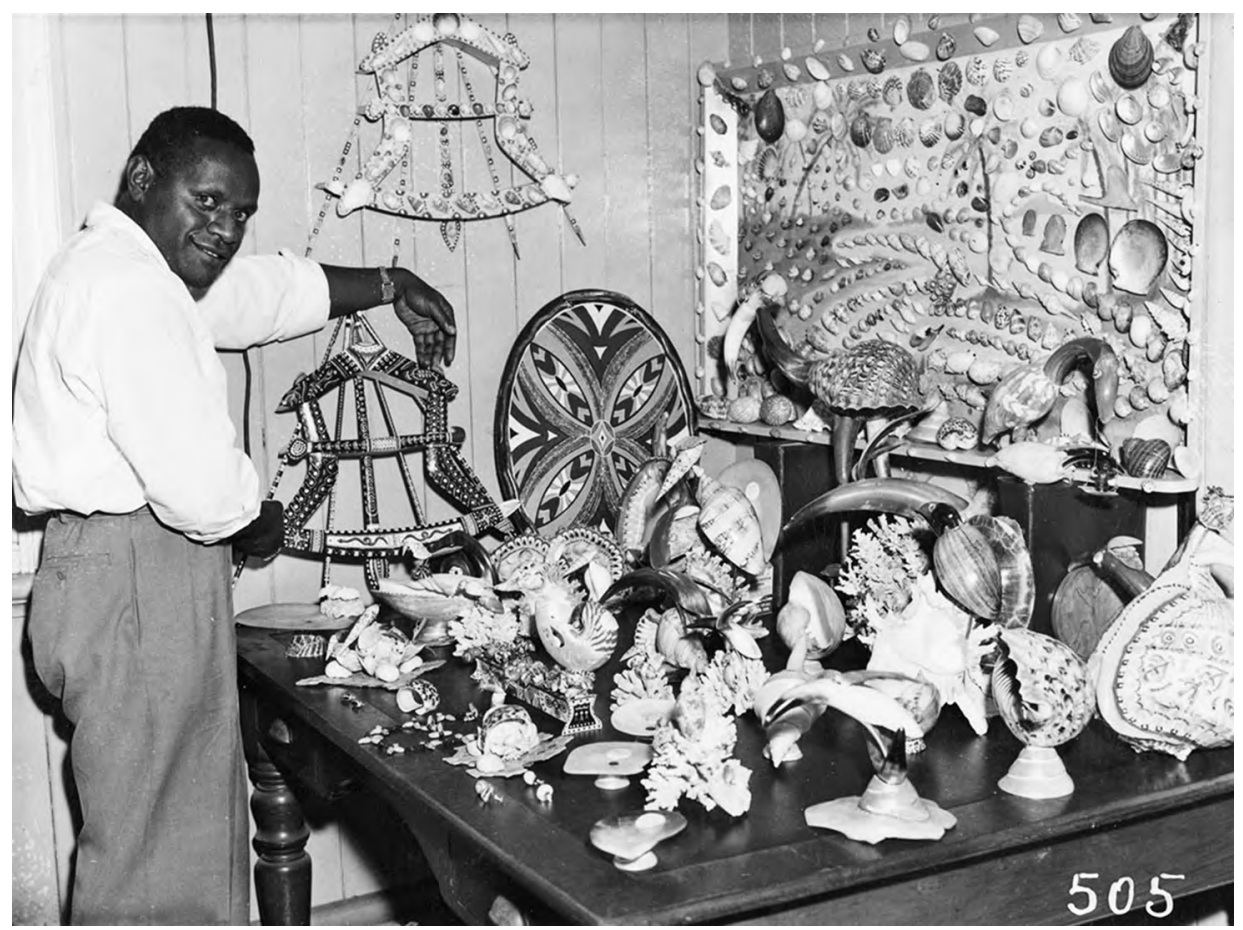

Figure 1: Geoffrey Doolah, setting up the Aboriginal arts and crafts and shell display for the Native Affairs Department at the Cherbourg Aboriginal Community, 1958.

Source: Queensland State Archives (QSA Item ID435956, Photographic material).

6 Burton, The Re-Establishment of the Indians in Their Pueblo Life; Potter, 'James Houston, Armchair Tourism, and the Marketing of Inuit Art'.

7 Stolte, Aboriginal and Torres Strait Islander Art, 29.

8 Queensland Tourist Bureau's itemised inventory sheet, c. September 1933, QSA Item ID336275.

9 J. W. Bleakley to the Protector Thursday Island, memorandum, 19 December 1933, QSA Item ID336275. 
In 1958, for example, the Native Affairs Department (as it was identified) set up a display of crafts and shell work at the then Cherbourg Aboriginal Mission (Figure 1). ${ }^{10}$ Geoffrey Doolah, a Torres Strait Islander man, is photographed setting up the display. Unnamed in the Native Affairs Department's records, his identity was revealed during the course of curating the exhibition. ${ }^{11}$ The lack of naming is not unusual as photographs from this period were used for promotional materials to support the continued efforts of the department and its goal for economic prosperity. The act of curation and research can often bring these identities to light and, indeed, it is often the only way in which these identities are reclaimed.

The first 1933 window display proved successful and demands for artefacts by the general public soared. The Department of Native Affairs decided to capitalise on this demand. In the 1950s, the department sent representatives to communities all across the state and into the Torres Strait Islands. Each community was envisioned as a production centre for particular artefacts. Hope Vale was seen as being perfectly placed to produced bark paintings for sale and bark 'blanks' for distribution to Mornington Island and Brisbane for artists to paint and then sell. Cherbourg was targeted for boomerang production and shops were set up for the purpose of mass production. The Torres Strait Islands were the hub of shell-collecting, stringing and weaving. ${ }^{12}$

In 1959, the Department of Native Affairs officially launched Queensland Native Creations (which was later changed to Queensland Aboriginal Creations in 1967). ${ }^{13}$ Queensland's Department of Native Affairs was now engaged in the mass production of artefacts on a large scale. This engagement was heavy-handed with the department overseeing all aspects of production. Quality control was a topdown process. Boomerangs, for example, were scrutinised by QAC managers and the public for not returning properly or being the wrong shape. Managers sent out memos to communities dictating the proper shapes of boomerangs in an attempt to cater to the desires of buyers. ${ }^{14}$ Other complaints by customers included the timeliness of delivery (often orders were not filled fast enough) or if they appeared to be made using contemporary saws and sanders. ${ }^{15}$ The demand for a timely product, shaped according to expectations and made by traditional methods, was made with complete disregard to what was always a time-consuming and individual process.

10 The community at Cherbourg is now referred to as the Cherbourg Aboriginal Shire Council. See their website cherbourg.qld.gov.au/ for more information. Accessed 15 November 2019.

11 Special thanks to Nancy Bamaga for helping me identify Geoffrey Doolah. Further research is in progress to contact Geoffrey's family as Doolah was a major figure at Cherbourg yet his story is still relatively unknown.

12 QSA Item ID502314. See also Stolte, Aboriginal and Torres Strait Islander Art, 31-35, for a more detailed account of these developments.

13 QSA Item ID502314.

14 J. W. Bleakley to Yarrabah's superintendent, c. September 1933, QSA Item ID336275.

15 QSA Item ID336275. 
The production of bark paintings was also a heavily regulated industry. Hope Vale wanted to engage in bark painting production but QAC managers felt that paintings from Mornington Island 'sold better'. Craftspeople from Hope Vale were thus encouraged to make bark blanks that were shipped to Mornington Island and then Brisbane for sale. ${ }^{16}$ Continuing to have their own artistic capabilities ignored, Hope Vale ended up producing almost all the bark blanks for Brisbane artists as well. Despite the lack of support, Hope Vale artists continued to produce paintings on bark. Agency and Legacy has three walls of bark paintings on exhibit in order to highlight this act of agency by Hope Vale artists. Through donations from private collectors, the Queensland Museum is fortunate enough to have dozens of Hope Vale bark paintings, clearly illustrating that, despite the lack of support, artists still produced what they wanted to produce. The paintings showcase the local flora and fauna of the Cape York region including images from the rock art panels, local artefacts and basket styles and, for artists like Roy McIvor, his own stories growing up on country. An imported medium, bark paintings were used to tell local stories.

Bark paintings are a particularly poignant medium to illustrate the level of involvement the state had in artefact production. During the 1960s, bark paintings from the Northern Territory, especially from communities in Arnhem Land, were selling well and being actively collected and published by anthropologists. ${ }^{17}$ The Department of Native Affairs saw the popularity of bark paintings as another way for Queensland artists to engage in the market with a product that already had a great deal of public appeal. More than 20 Arnhem Land bark paintings were photographed and made into a booklet that was distributed to artists in Brisbane for copying. The Hope Vale bark blanks were handed out for Brisbane artists to copy Arnhem Land images. Orders forms were available to the public and one could order a 'Milky Way No 8' (it was the eighth image in the book) in a small, medium, large or extra-large size (Figure 2) ${ }^{18}$ Such a practice is anathema to today's understanding of Aboriginal and Islander cultural and intellectual copyright, and the exhibition was at pains to put these paintings in a different light.

16 I. V. Istead to the Hope Vale Manager, 5 March 1968, QSA Item ID646444.

17 See Ryan, Spirit in the Land; Morphy, Becoming Art.

18 Invoice from Australian Aboriginal Creations to QAC, 1 July 1969, QSA Item ID504813. 


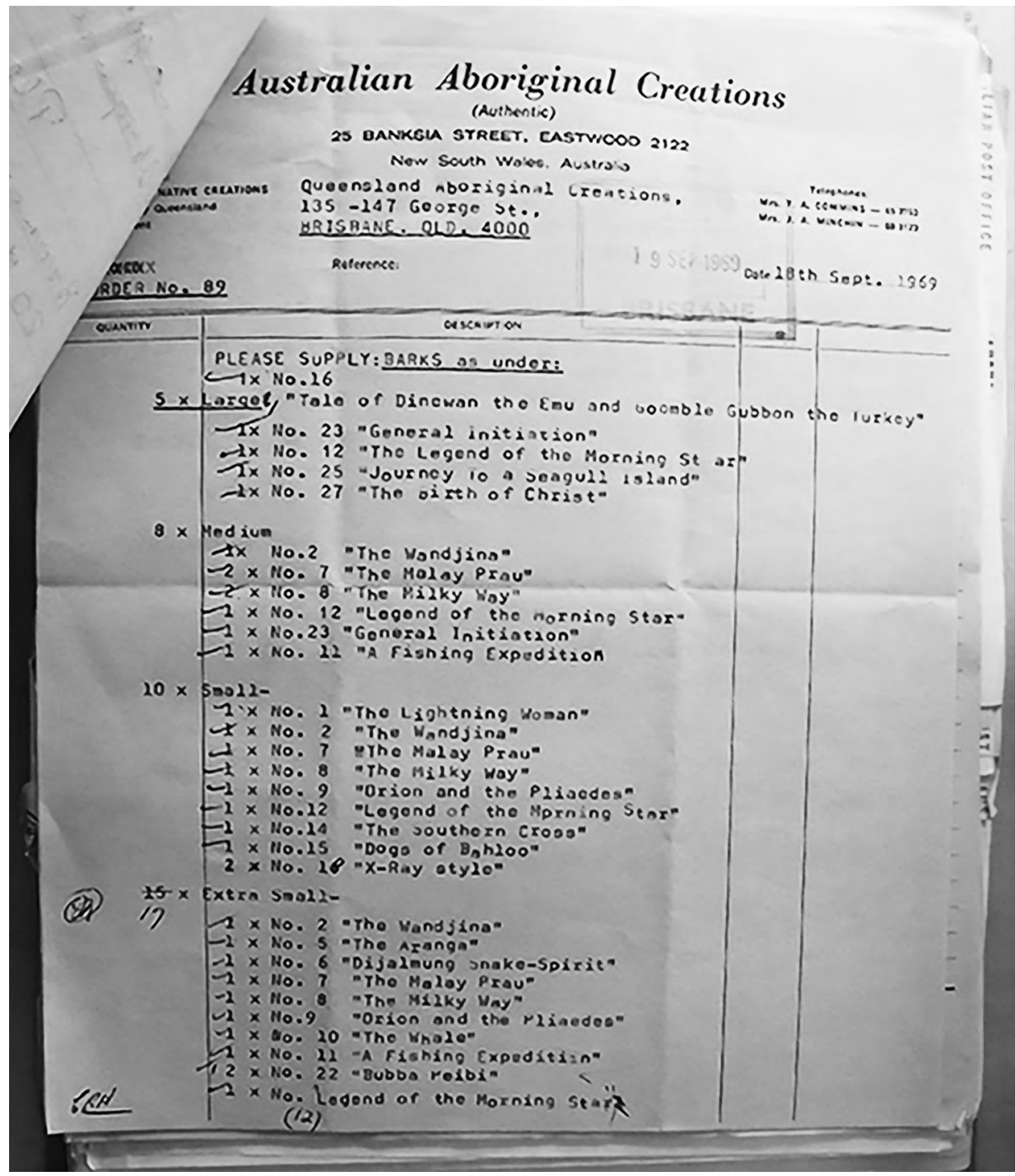

Figure 2: A sample of an order from Australian Aboriginal Creations shop in New South Wales to Queensland Aboriginal Creations.

Objects listed are named according to the QAC catalogue that was distributed for facilitating orders such as these. Note the requests from outside Arnhem Land such as Western Australian Wandjina paintings and even Christian themes such as 'the Birth of Christ'.

Source: Queensland State Archives (QSA Item ID504813, Photographic material). 
One of the ways in which this exhibition tackled the problem of cultural infringement was to not hide it. The UQ Anthropology Museum is fortunate enough to have an example of Milky Way No 8. This and three other paintings are showcased as examples of this tense history. ${ }^{19}$ The exhibition acknowledged the copying by titling the larger text panel next to these barks as 'Other People's Stories', stating outright that what was painted was not the artist's story but someone else's. The focus in the exhibition, however, is to show how artists strayed away from direct copying and exercised their own creative licence. Individual text panels pointed out to visitors the points of innovation in the bark paintings. In particular, the border flourishes and decorations of the top and bottom registers in the bark paintings all indicate points of divergence from Arnhem Land styles. Such analysis will be explored further in subsequent publications but as will be no surprise to anyone, bark painting is not a tradition that has continued much to this day. There are very few artists who are practising in this medium in Queensland. There are, however, a great number of artists who are crafting and selling artefacts, and it is to the production of artefacts that this article will now turn. ${ }^{20}$

\section{Artefacts}

Although the archives reveal some grumbling about the production of spears and shields (boomerangs sold better), communities still produced and shipped numerous artefacts throughout QAC's decades of operation (Figure 3). These activities maintained the production of these traditional Queensland artefacts and facilitated the passing down of these knowledges, which might have been lost otherwise. The UQ Anthropology Museum has an incredible collection of these lesser known and less talked about QAC artefacts from across Cape York. Bought by a rare forwardthinking director, the collection included spear throwers, spear tips, clubs and pronged fishing spears. These were highlighted in the Agency and Legacy exhibition in order to expand the public's perception of QAC beyond just facilitating the sale of boomerangs. These artefacts are based on cultural traditions preceding colonial contact as well as any museum interest and collection practices. John Conroy, the manager of QAC during the late 1980s, remembers going through shipments that came from the Cape and seeing what he thought were incredible ethnographic finds. Conroy showed such objects to museums to see if they wanted 'first crack' at purchasing them; but even these artefacts were rejected because anything that came through QAC was seen as tainted by the tourism market. ${ }^{21}$

19 Out of respect for the original artists and stories these paintings represent, these paintings will not be published here.

20 For more on the history of bark paintings in Queensland, see Aird, Brisbane Blacks; and Stolte, Aboriginal and Torres Strait Islander Art.

21 John Conroy, in conversation with the author, 5 October 2019. 


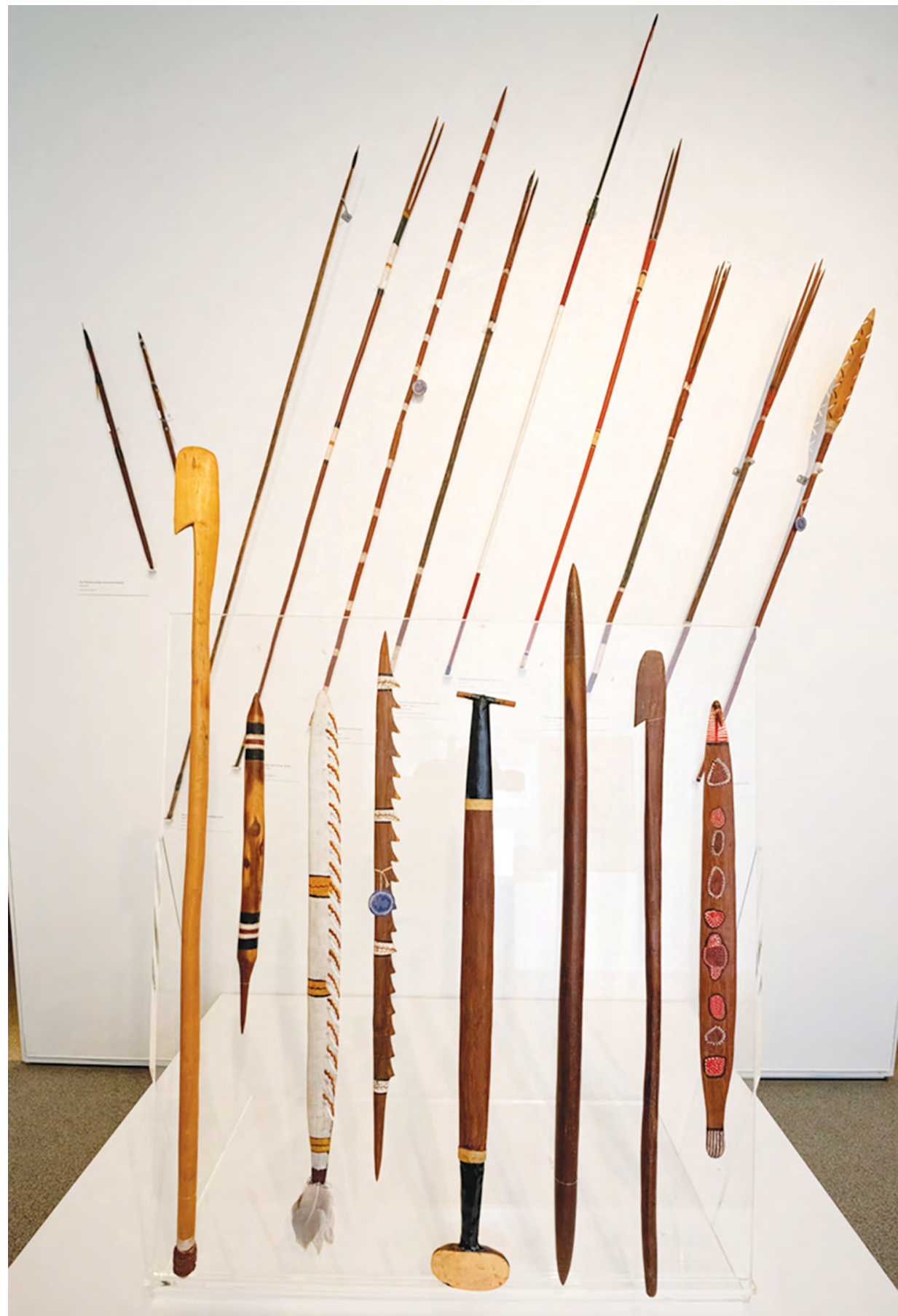

Figure 3: Cape York artefacts from various communities including Mornington Island, Aurukun, Kowanyama and Bamaga, before 1973. Acquired through Queensland Aboriginal Creations by the UQ Anthropology Museum.

Source: Photograph by Mick Richards. 
This taint extended beyond the buying of artefacts and into the representation and publication of the QAC story. Currently, there are only a handful of publications that even mention QAC and most of those focus solely on the breaches of cultural copyright surrounding the bark paintings from Arnhem Land. ${ }^{22}$ Michael Aird's Brisbane Blacks ${ }^{23}$ is the first publication to include the voices of the artists involved, and Stolte's chapter on the history of QAC in Aboriginal and Torres Strait Islander $A r t^{24}$ is the only publication that delves into the policy ramifications of QAC's actions. The exhibition at the UQ Anthropology Museum was designed to bridge some of these publication gaps by connecting the material culture of QAC to archival documentation. Through these efforts, a re-examination of some of the assumptions put on those objects - the 'taint' of the tourism market - are unravelled. ${ }^{25}$

Boomerangs were the hallmark of QAC's curio shop. Although it was always filled with a variety of objects and paintings, boomerangs stood as the quintessential Australian souvenir and, therefore, were always well-stocked. Importantly, boomerangs were never (and continue not to be) uniform in design and decoration; Mornington Island boomerangs, for example, are quite distinct. Two Mornington Island boomerangs are on display in Agency and Legacy (Figure 4) and represent a host of artefacts made in the same ways as before the arrival of Europeans on the continent. These boomerangs are commonly painted on one end in white ochre with red ochre strips and are rarely decorated in any other way. These Mornington Island boomerangs are part of that collection of artefacts the UQ Anthropology Museum purchased from QAC, making the collection a valuable insight into those works.

The bottom line though is that most of the artefacts that went through QAC were not viewed as favourably. Mornington Island boomerangs are found in many museum collections across Australia but many were collected on country by collectors and researchers. ${ }^{26}$ Boomerangs such these are perceived differently to boomerangs that are made particularly for tourist sale. In point of fact, there seems to be a 'boomerang as artefact' and 'boomerang as tourist object' dichotomy. As spears, shields, woomeras and other artefacts do not seem to consistently share this dichotomy, ${ }^{27}$ a discussion on boomerangs specifically is both fascinating and interesting.

\footnotetext{
22 Kleinert and Neal, The Oxford Companion to Aboriginal Art and Culture, 187; Anderson, 'The Aboriginal Art Industry in Cairns', 119; Demozay, Gatherings II, 18.

23 Aird, Brisbane Blacks.

24 Stolte, Aboriginal and Torres Strait Islander Art.

25 Unfortunately, tight time frames and limited budgets prevented proper community collaboration but efforts to remedy that are currently underway.

26 See Best, 'The Aboriginal Material Culture of the Wellesley Islands'.

27 There is in point of fact a growing niche market for other material culture objects made for tourism markets such as miniatures, like shields, coolamons (wooden containers) and woomeras, but they need their own treatment separate from the scope of this article.
} 


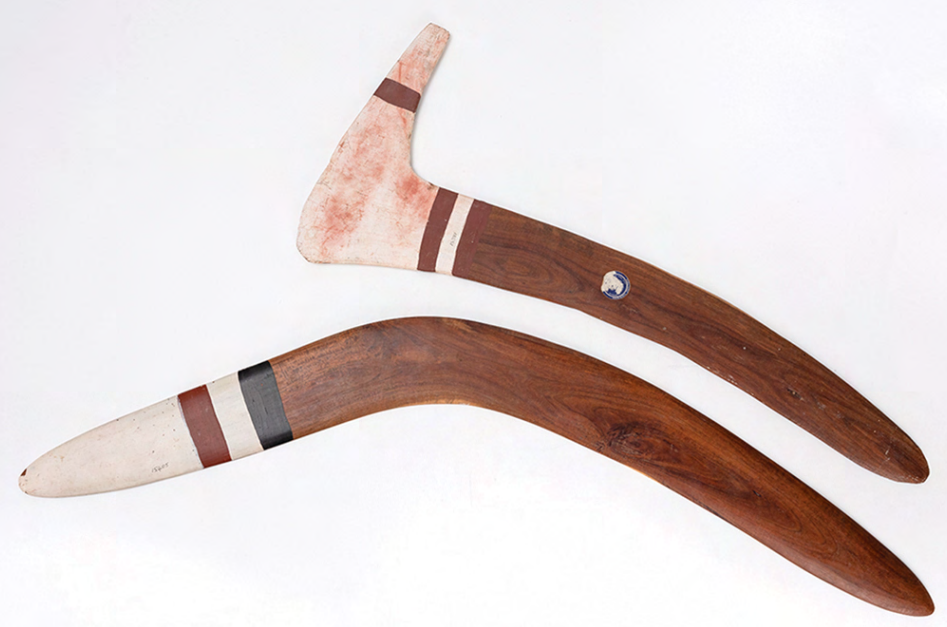

Figure 4: Mornington Island boomerangs - hooked boomerang (top) and hunting boomerang (bottom), before 1973. Acquired through Queensland Aboriginal Creations by the UQ Anthropology Museum.

Source: Photograph by Carl Warner.

\section{Boomerangs}

Boomerangs have been part of Aboriginal people's material culture for thousands of years, with the oldest known boomerangs being almost 10,000 years old, ${ }^{28}$ and are often called Australia's national symbol. ${ }^{29}$ Museum anthropologist Philip Jones writes that the boomerang 'has been used over and over in the long process of Australian identity formation, taking its place with the world's great cultural symbols' ${ }^{30}$ Boomerangs, however, are also 'an important element of contemporary Aboriginal art, serving as "canvases" for individual artistic expression. ${ }^{31}$ Crucial to this discussion is the fact that decorated boomerangs are an old art tradition and not just a product of tourism efforts or even cross-cultural encounters or

28 Jones, Boomerang, 9.

29 'Boomerang - a National Symbol', Lawrence Wilson Art Gallery, 14 February 2020, accessed 24 May 2020, www.lwgallery.uwa.edu.au/exhibitions/boomerang; 'Boomerang: Souvenir Becomes a National Symbol', National Museum of Australia, n.d., accessed 24 May 2020, www.nma.gov.au/exhibitions/symbols-australia/boomerang.

30 Jones, Boomerang, 5.

31 Jones, Boomerang, 27. 
colonial processes. In 1953, Tindale recorded rock art at Port Hedland that included "18 "plain" and 15 "decorated" boomerangs. ${ }^{32}$ Rock art from this area is reportedly 10,000 years old ${ }^{33}$ suggesting that decorated boomerangs are as old as the artefact itself. Furthermore, the diversity of designs in the Port Hedland record is quite extraordinary ${ }^{34}$ and should confirm that decoration is not a new modification.

One of the biggest hurdles in the consideration of boomerangs is the fact that boomerangs are often associated with travel souvenirs and the tourist industry in general. As already pointed out, Conroy experienced extreme reluctance from Queensland museums to collect anything filtered through QAC. The objects were seen as QAC objects and not objects that reflected Aboriginal identity or culture. As Ruhanen and Whitford write so eloquently, we must seek to gain a more wholistic [sic] understanding of the role Indigenous cultural identity and cultural representation plays in the sustainable development of cultural Indigenous tourism products'. ${ }^{35}$ Although QAC did not operate in any way like cultural tourism does, the concept of culture as commodity has a great deal of overlap between Indigenous tourism and QAC's operations of mass production. Just as Bleakley tried to instruct communities on the proper shape of boomerangs, there is a sense that 'Indigenous identity is often reconstructed to satisfy tourist expectations. ${ }^{36}$

Boomerangs need to be seen as representations of 'the dynamic interaction between modernity and tradition'. The assertion that 'tourism threatens Indigenous identity and culture' also needs to be questioned. ${ }^{37}$ In curating Agency and Legacy, these concepts were challenged in various ways. The first method was to incorporate contemporary boomerang makers to illustrate the legacy of boomerang making and to include First Nation voices in the exhibition. The archives rarely name an artefact maker so including contemporary stories allows for artists to control some of the exhibition narrative. The second method was to showcase historical boomerangs in a way that asks visitors to rethink the artefact as a work of art.

In considering boomerangs as art, the exhibition highlights the range of painted images that boomerangs can carry. The exhibition also corrects the lack of awareness around how cultural knowledge and connection to country are facilitated by exploring boomerang production. Boomerang making is at the core of cultural continuity and those made for the tourist market are often heavily laden with cultural knowledge and the life experiences of Aboriginal peoples. It is not a question of 'even tourist boomerangs' have cultural meaning and importance as the implied hierarchy has no constructive place in discussions around contemporary artefact

\footnotetext{
32 Harper, 'Engraved Material Culture in a Fluid Landscape', 44.

33 Harper, 'Engraved Material Culture in a Fluid Landscape', 42.

34 Harper, 'Engraved Material Culture in a Fluid Landscape', 49.

35 Ruhanen and Whitford, 'Cultural Heritage and Indigenous Tourism', 181.

36 Ruhanen and Whitford, 'Cultural Heritage and Indigenous Tourism', 181.

37 Ruhanen and Whitford, 'Cultural Heritage and Indigenous Tourism', 183 and 182, respectively.
} 
production. There are quality issues - some decorations are poorly executed and some constructions are hastily done. I want to set the issue of quality to one side, however, and highlight instead how cultural meaning and importance are imbued in boomerang production.

Garth Murgha and Estelle Tranby of Native Creations Australia have been producing artefacts for the Cairns tourism market for over 20 years. Before embarking on their own, they were part of the Deeral Aboriginal Co-op. Based in Babinda, a small community near Cairns in Far North Queensland, Deeral was one of many small supply hubs for QAC where local artists and artefact makers produced boomerangs and painted barks. Garth Murgha created boomerangs and artefacts for the Deeral Co-op while Estelle Tranby painted boomerangs and barks. All of these works were shipped to Brisbane for sale. She recalls that her colour palette was like many other palettes during that time and only utilised earth tones and natural ochre colours. ${ }^{38}$ Estelle's colour palette has changed in the decades since and she now paints in a colour spectrum that reflects more of the vibrant life of the surrounding rainforests. Her paintings are now on canvas and full of colour, rendering aspects of Djabugay environmental and cultural life.

Boomerangs continue to be the cornerstone of Garth and Estelle's economic stability. They use native timbers for their works emphasising the natural wood grain of the ironbark, wattle and gum trees they use. Despite the craftsmanship of both Garth's fine wood working and Estelle's artistry, the market still dictates aspects of their work. As noted elsewhere, the tourist market in Cairns only allows for a limited range of pricing on boomerangs - such works generally sell between $\mathrm{A} \$ 20$ and $A \$ 25$ because that is what buyers are willing to spend. ${ }^{39}$ Highly crafted native timber boomerangs make up one part of their offerings but the market cannot always accommodate the associated costings. Garth and Estelle's solution is to diversify by incorporating plywood boomerangs as part of their production. These fully painted plywood boomerangs provide the opportunity to produce a quality product while making the most of resources and time. However, I do not want to replace one hierarchy with another (native timbers over plywood). What is important to note here is the deliberate and economic choice to respond to the market in a thoughtful and considered manner. This response though is not without cultural considerations.

I have been buying boomerangs and artefacts from Native Creations Australia since 2010. Garth and Estelle are regular fixtures at the Cairns Weekend Markets, held every Saturday on the Esplanade. The Esplanade in Cairns is a strip several blocks long next to the inlet where the majority of tourists 'hang out' between their explorations of the rainforests and the Great Barrier Reef. The weekend markets themselves are a mix of the handmade and the mass-produced. Garth and Estelle's outdoor stand

38 Personal communication, 20 January 2020.

39 Stolte, Aboriginal and Torres Strait Islander Art, 134. 
is often the only First Nations stand selling locally made Aboriginal artefacts. For over 20 years their stand has certainly been the most consistent presence. In 2019, Garth, Estelle and I began working together to produce new understandings of artefact production in Far North Queensland. When I was hired to curate Agency and Legacy, I was eager to have them on board.

Garth Murgha is from the Gungandji tribe, located at Yarrabah, while Estelle Tranby is from the Djabugay tribe near the Kuranda tablelands. Their company produces multiple types of boomerangs including hook, returning, club and cross. Garth also creates fire sticks, rainforest shields and swords. Garth does the wood manipulation himself, salvaging the natural timbers from the rainforests surrounding his Babinda home. In the beginning, the boomerangs and artefacts were all hand carved but demand increased so much that an industrial-sized bandsaw was needed to keep up with the over 200 boomerangs sold each month. Estelle Tranby paints designs on the artefacts that reflect her own traditional bush medicines, life on country and ceremonies. Artefacts made from native timbers are painted minimally in order to highlight the beauty of the wood grain. Estelle learned to paint from her father Enoch Tranby and through the creation of 'piecework' while participating in artefact production through the Deeral Aboriginal Co-op. Piecework included boomerangs but also small portable paintings, easily carried home by overseas tourists. Together, Garth and Estelle make a powerful team, creating well-crafted works for purchase. Their inclusion in the exhibition is part of a larger strategic concept of rethinking boomerangs and their cultural significance in Queensland. This rethinking is helped through the exhibition layout.

In planning Agency and Legacy, a smaller space off from the main gallery at the UQ Anthropology Museum was ideal for highlighting and providing focus for a rethinking of boomerangs (Figure 5). From the very beginning, I felt that the three walls of this space were perfect for telling the story of artefact production by situating the boomerangs as artworks and objects of agency.

The first wall of the back gallery is filled with undecorated QAC boomerangs, many by unnamed artists. Shipments of artefacts would be sent down to Brisbane and sold to tourists. Money would be sent back to the communities and redistributed to artisans, encouraging further production. Because of this process of reimbursement between QAC and communities, the State Archives has few details about the boomerang makers. However, that does not mean that we know nothing about these artisans. Despite the many mandates surrounding the proper shape of a boomerang dictated by QAC in the early years, the shapes of boomerangs are hardly uniform. Aboriginal craftspeople produced a variety of boomerang styles that we can read as forms of agency against those mandates. This first wall was dedicated to showcasing the agency that is the diversity of shape in boomerangs. 


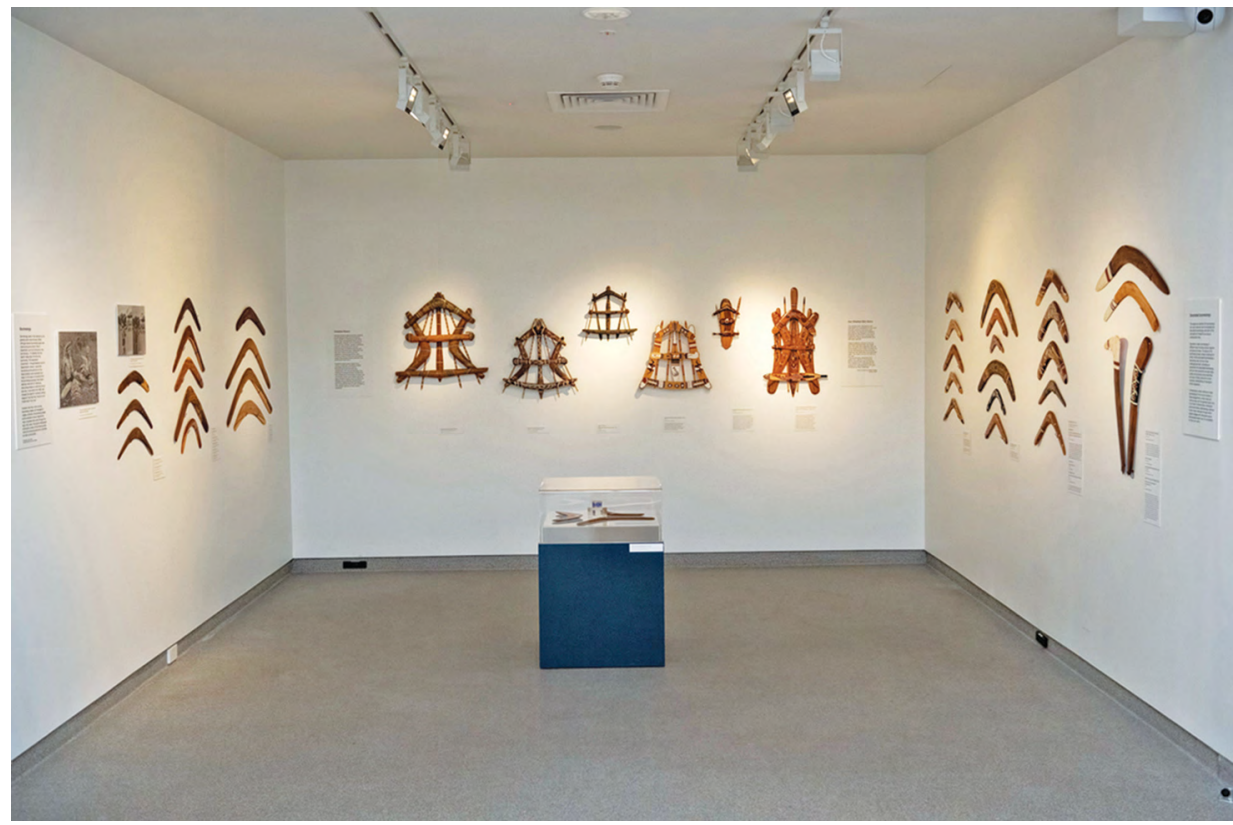

Figure 5: Artefact production walls at the UQ Anthropology Museum.

From left to right: undecorated boomerangs, shadow boxes, decorated boomerangs. Various collections including private, UQ Anthropology Museum and the Queensland Museum.

Source: Photograph by Mick Richards.

The third wall is filled with decorated boomerangs. (The second, centre wall is dedicated to shadow boxes, which will be discussed below.) As already mentioned, decoration is an old tradition for Aboriginal people and it should not be seen as modification for the tourist industry. The motifs may be modified for a tourist market but the tradition of painting boomerangs is not. Howard Morphy has written extensively about how Yolyu bark paintings intended for sale are modified in order to remove the more secret and sacred components behind the imagery and stories being told through the act of painting. ${ }^{40}$ Unlike boomerangs though, bark paintings are highly valued and collected by museums and galleries. ${ }^{41}$ Many of the bark paintings displayed during the National Museum of Australia's blockbuster exhibition Old Masters: Australia's Great Bark Artists were made to be taken out of Aboriginal communities and shared with a wider world..$^{42}$ The reception of bark paintings though has been radically different from painted boomerangs. This third wall of the exhibition asks why that difference exists. Is it simply because boomerangs are mass produced?

40 See Morphy, Becoming Art.

41 Morphy, Becoming Art.

42 National Museum of Australia, Old Masters. 


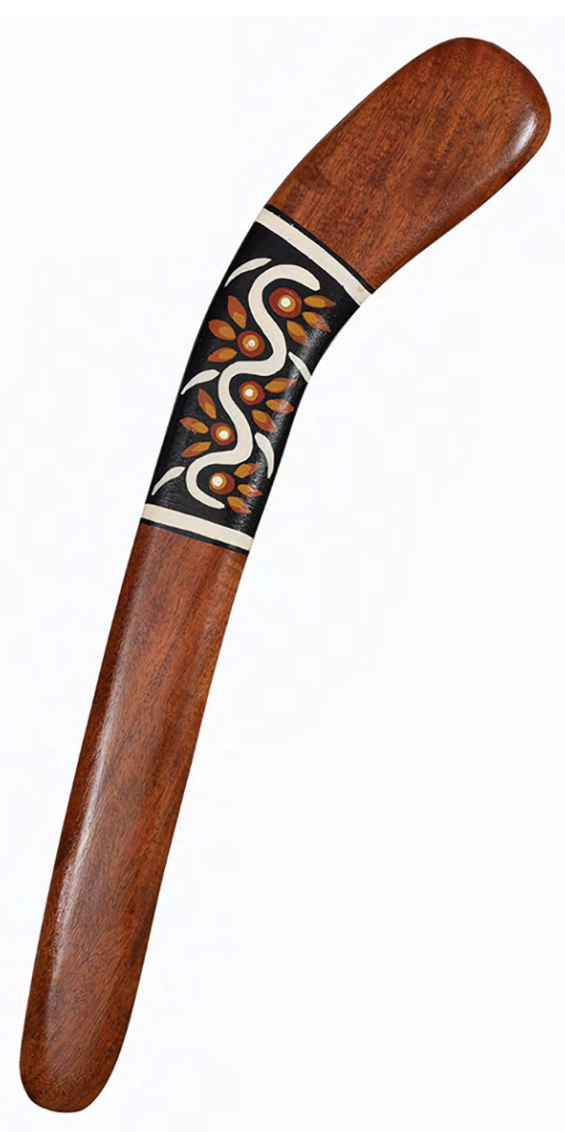

Figure 6: Club boomerang crafted by Garth Murgha and painted by Estelle Tranby, 2018. Black wattle wood with acrylic paint. Private collection.

Source: Photograph by Carl Warner.
Decoration codes boomerangs in different ways including the cultural, regional and personal. The shape of the boomerang poses a design challenge for artists, making decorated boomerangs a fascinating view into how those challenges are met. Cultivating an appreciation for decorated boomerangs, and how their production and sale helps sustain and promote cultural identities and ways of being, allows for a more nuanced understanding of Aboriginal artistic expression. In market engagements, artists meet and communicate with the general public who in turn learn first-hand about Aboriginal culture and history. Boomerangs continue to be a major doorway through which people engage with Aboriginal culture and peoples.

One of the boomerangs on display in the exhibition is a club boomerang crafted by Garth and painted by Estelle (Figure 6). The wood is black wattle (Acacia mearnsii), a native tree in the rainforests around Cairns. Garth and Estelle team up to tell stories and showcase their heritage through works such as this one. The club boomerang was an important tool for Aboriginal people and the painted design is of lawyer cane, an important resource in its own right. Lawyer cane (Calamus caryotoides) was (and continues to be) harvested for weaving baskets and bags and binding things together. The decoration of the club boomerang depicts the spikes of the cane along with their flowers and leaves - the dots being the fruit. 
I bought this club boomerang at the Cairns Saturday markets in 2018. The meaning of the painting was explained to me as well as the wood type. Observing Garth and Estelle at the markets is a repeat of this same pattern. Visitors approach the stand and marvel at the array of works on display. They listen as Garth explains the different types of boomerangs and Estelle describes the meanings behind her paintings. Each are enthusiastic about their works as expressions of their cultural heritage. Garth is the more vocal of the two, easily engaging with all the visitors. Estelle is more quiet but is always ready to discuss her very detailed and well-thought-out paintings.

The importance of these exchanges cannot be underestimated. Tourists who visit Cairns come from all over Australia and all over the world. Aboriginal culture is often in the public view via outdoor events and festivals, museum exhibitions and cultural tours but direct one-on-one engagements are rare. Visitors do not always have the opportunity to casually talk to the First Nation peoples of Australia, nor do they have an agenda to do so. ${ }^{43}$ Research suggests that engaging with First Nation Australians is a low priority for tourists. ${ }^{44}$ Being part of a large marketplace allows for casual and spontaneous engagement and education. Garth and Estelle are representatives of their respective tribes but they are also putting themselves out there in the public for anyone curious about Aboriginal culture in Australia. Based on my observations at the markets, questions from visitors include queries on traditional foods, language names, traditional weapons and hunting techniques and, always, about the 'meaning' of artworks. People who are not inclined to go to a museum or pay for a tour get a short-course in Aboriginal culture through these market engagements. The value and importance of these cross-cultural engagements cannot be underestimated.

Decorated boomerangs and their sale at markets or through QAC should not be reduced to a mere economic exchange. We also need to reject the automatic assumption that there is a modification of culture to meet tourist expectations rather than the fulfilment of cultural needs of the artists. Cultures change and adapt, and our analysis of decorated boomerangs needs to as well. In communicating with the public, Garth and Estelle utilise the space to communicate their cultural heritage while sustaining their family economically. It is not performance as some write, ${ }^{45}$ but is instead a form of commodified persona, protecting the Indigenous self while communicating enough to educate and entertain. ${ }^{46}$ Boomerangs like Garth's and Estelle's and indeed all the decorated boomerangs in Agency and Legacy facilitate and have facilitated cultural exchange and cultural continuity. This point is emphasised through a short video documentary. Juxtaposed with the

43 Ruhanen, Whitford and McLennen, 'Indigenous Tourism in Australia', 79.

44 Ruhanen, Whitford and McLennen, 'Indigenous Tourism in Australia', 79.

45 Jones, Booth and Acker, 'The Changing Business of Aboriginal and Torres Strait Islander Art', 108.

46 Bunten, 'Sharing Culture or Selling Out?', 382. 
boomerang wall, interviews with contemporary makers allow them to tell their stories and show their processes. This documentary connects the past and the now, the process and the product.

\section{Shadow boxes}

Boomerang manufacturing produced an innovative offshoot of artefact production - the shadow box. First crafted in Cherbourg and then Hope Vale and Babinda, they are an amazingly creative use of artefacts and are highlighted in the exhibition on the second, centre wall of the small gallery (Figure 5). Shadow boxes are composed of various artefacts depending on the preferences of the maker. These artefacts include smaller, often miniature, shields, spears, rainforest swords, woomeras (spear throwers) and various boomerangs including hunting, club and returning. Although not the only artists working in this tradition, Cherbourg artists Jack O'Chin, Arden O'Chin and Joe Skeen popularised the shadow box form. Joe Skeen and his family were heavily involved in boomerang production and his shadow boxes are robust examples of the medium (Figure 7). ${ }^{47}$ There are several stylistic differences as each artist puts their own spin on them. Some shadow boxes used delicate interpretations of artefacts while others preferred thicker articulations. Hope Vale artists had their own interpretation entirely, making their shadow boxes based on shields topped with spears and boomerangs. Most shadow boxes were elaborately painted with the artefacts made of either native woods or readily available plywood. ${ }^{48}$

Shadow boxes are a uniquely Queensland creation, reflecting both the legacy of the commercial efforts of QAC as well as the artistic agency of the artists involved. Since the late 1980s, the making of shadow boxes ceased but in 2019, Garth Murgha and Estelle Tranby decided to celebrate the 10th anniversary of the Cairns Indigenous Art Fair by making a series of shadow boxes. Inspired by their Elders, who were also part of QAC's curio production, Garth and Estelle revisited the shadow box with their own interpretation on the tradition. Each artefact has been individually carved and joined by Garth, the process of designing the shadow box taking some time and experimentation (Figure 8). Garth grew up with his Uncles making shadow boxes and his creations are meant to be both a homage to their processes as well as an opportunity to develop his own unique approach. After assembly, the artefacts are painted by Estelle. Each animal depicted represents life in the rainforests while the shadow box style continues the innovative tradition that began decades earlier.

47 Aird, Brisbane Blacks.

48 There are a few shadow box 'blanks' held at the Queensland Museum but these are rare pieces as shadow boxes are meant to be highly decorated. 


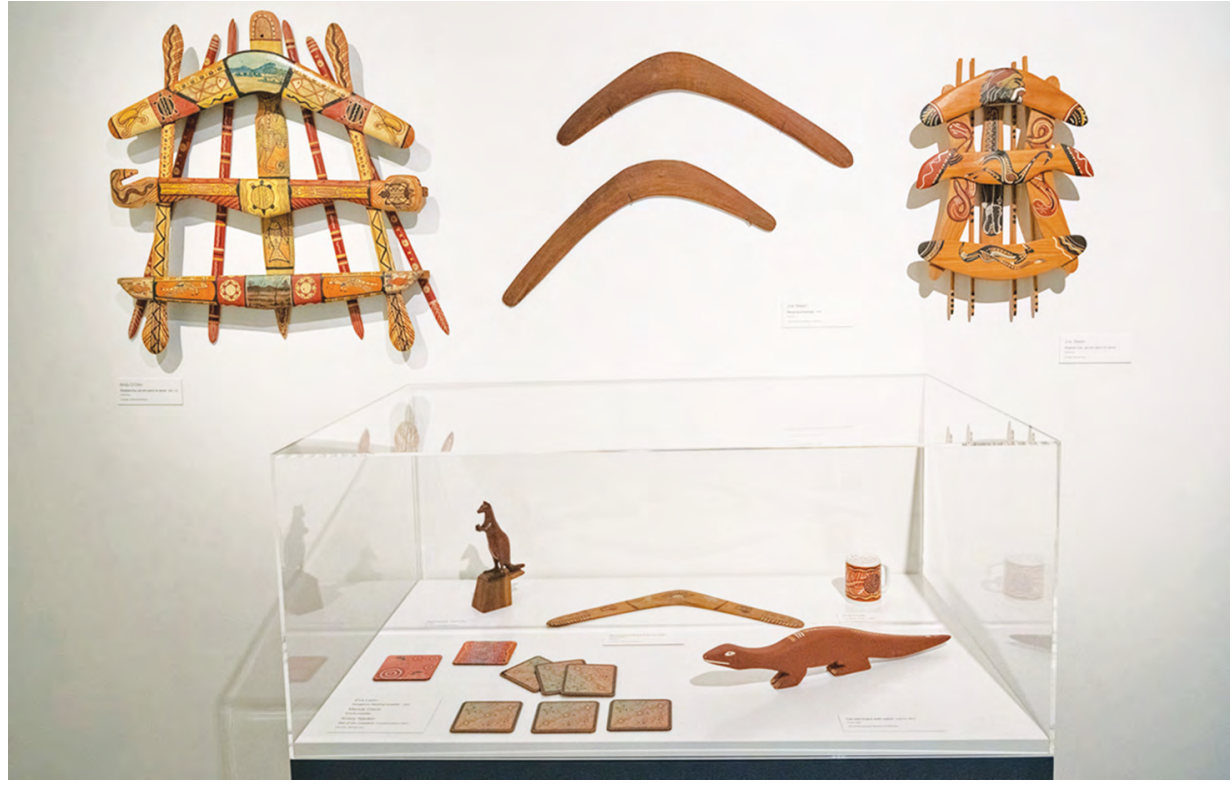

Figure 7: Exhibition introduction wall showing some of the range of QAC objects including (left to right) a Joe Skeen shadow box, two Joe Skeen boomerangs and an Ardin O'Chin shadow box. Various collections including private, UQ Anthropology Museum and the Queensland Museum.

Source: Photograph by Mick Richards.

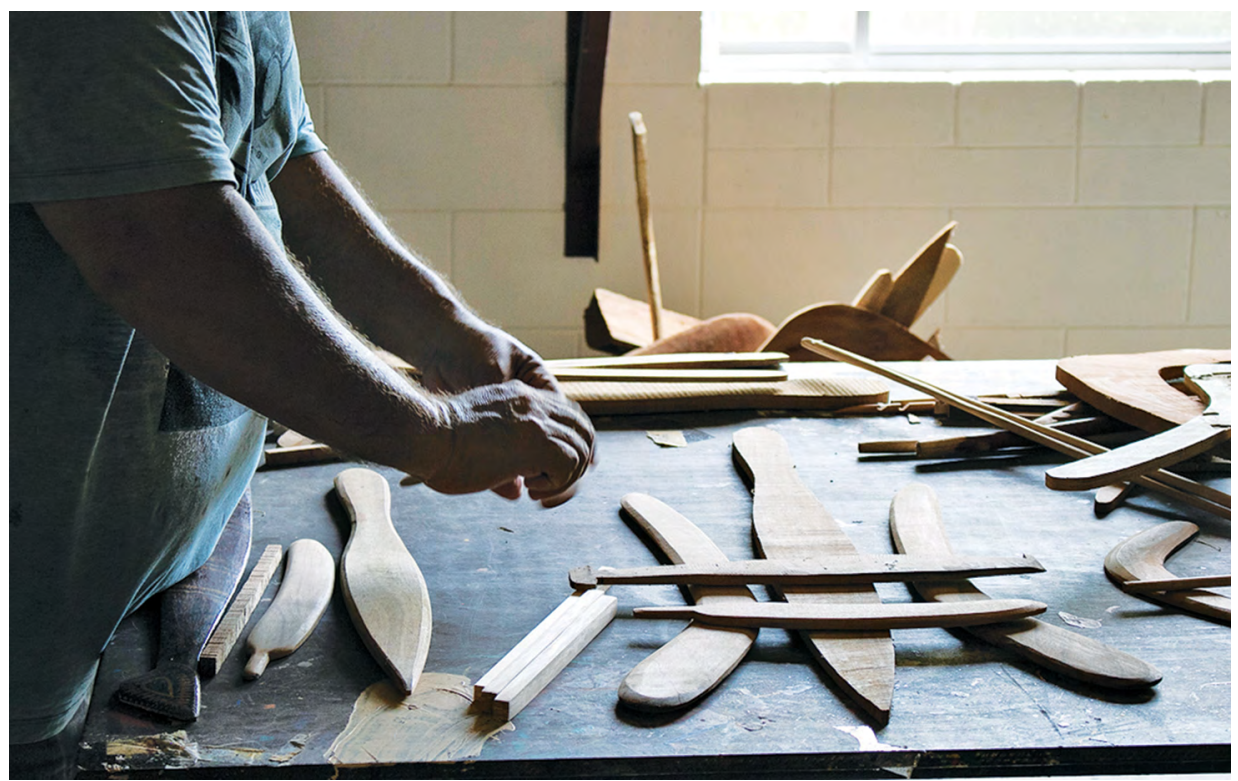

Figure 8: Garth Murgha laying out the various miniature artefacts that make up his shadow boxes, 2020.

Source: Photograph by the author. 


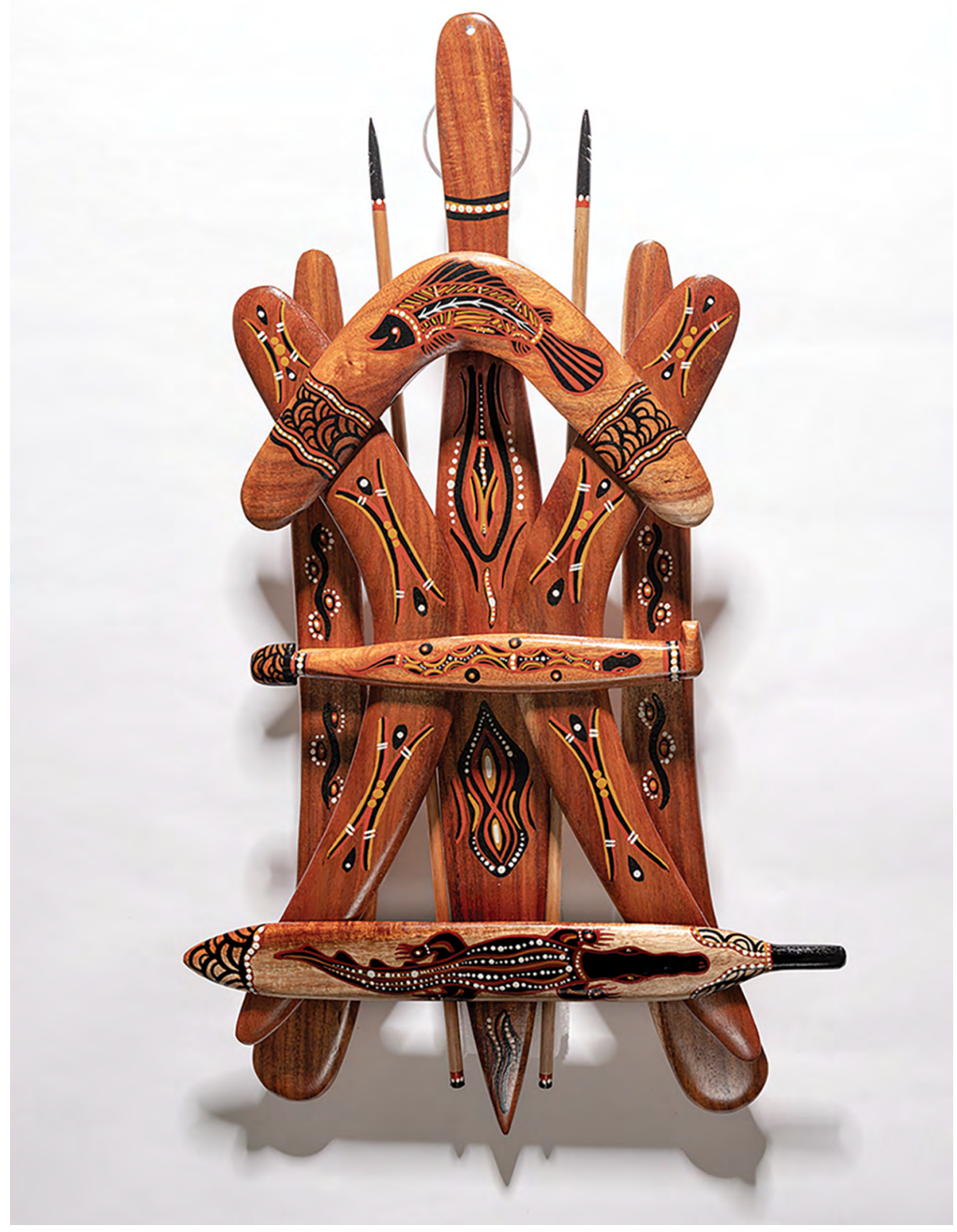

Figure 9: Shadow box crafted by Garth Murgha and painted by Estelle Tranby, 2019. Black wattle wood with acrylic paint. Private collection.

Source: Photograph by Carl Warner. 
The result of their efforts is indeed an original interpretation of the shadow box concept with one that is taller and narrower than others on display (Figure 9). Garth and Estelle write about the importance of shadow boxes themselves in order to communicate their cultural value to visitors:

\begin{abstract}
The shadow box represents and highlights our connection to our land and sea country. Physically and spiritually, the traditional artefacts attached to the shadow box are an important part of our cultural and traditional history as rainforest and saltwater people. These artefacts connect us to the rainforest because they are made from the basic raw materials that we have access to but it also connects us to the sea because of the tools and weapons we make from the rainforest trees. This helps us hunt for food on the reef. The boomerang, clapsticks and spears are used for hunting and dance ceremonies that are sacred. The shadow box is believed by our people as a representation of 'Luck', bringing us many blessings.
\end{abstract}

Their statement hangs next to their shadow box in the exhibition in order to communicate the cultural importance of the shadow box. This shadow box can be broken down into three layers of cultural artefacts. The back layer is composed of a single paddle flanked by two fish spears and two inverted club boomerangs. These are overlain by the second layer of two hunting boomerangs. The top layer, from top to bottom, comprises a returning boomerang, a woomera and rainforest sword. As Garth and Estelle write, a shadow box represents the cultural intersections of the sea and the rainforest. The motifs painted on each artefact extend this symbolism and include a barramundi, a crocodile, a sea snake, lawyer cane and people dancing. Garth and Estelle's shadow box and shadow boxes in general are inherently multivalent objects imbued with historical, cultural and social symbolism.

The creation of shadow boxes arose from QAC's boomerang industry. Ultimately though, they are the product of the ingenuity of the artists and their creativity, illustrating the high level of agency enacted by First Nations peoples living under these policies.

\title{
Broader issues of authenticity
}

The act of curation has the potential to create new information as well as express a vision of artistic presentation. The challenges for Agency and Legacy included developing an exhibition that was neither completely aesthetic nor completely ethnographic. In curating the QAC exhibition, one of the main challenges was the complex history surrounding all the objects created under its auspices. Selecting contemporary works to be displayed alongside historical ones was a method of bringing First Nation voices like Garth's and Estelle's into the gallery space. Many of the historical works in the exhibition such as strung necklaces, pottery, 
carvings and paintings sit next to their contemporary counterparts. These careful juxtapositions draw out the legacy of QAC's policies and actions but also the agency, self-determination and innovation of the artists both 50 years ago and today.

Agency and Legacy provided a platform for rethinking many aspects of artefact production in Queensland and the exhibition challenges visitors to see works in a new light, particularly boomerangs. Much has been written about the scientific principles of the boomerang. Their value in that regard is well-documented. Other writings around boomerangs focus on their ethnographic or archaeological value. When discussing the economic value of boomerangs, the focus is on fake importations from overseas. But boomerangs as art is slow to be understood. A key aim of Agency and Legacy was a re-examination of the boomerang as more than a tourist object for sale. Boomerangs are multivalent objects that need to be treated and considered as such.

The value of artefacts can be considered in several ways, including 'through the very process of their collection, documentation, movement, and flow through various hands' ${ }^{49}$ In already existing collections in museums, the concept of the duplicate is determined 'by distinctions such as place of collection and producer that are made by the collector as they document the collection' ${ }^{50}$ Both of these considerations are external to the understandings of the makers. The mass production of an artefact is said to change the value of an object and 'destroy the essence of the culture when the control of the cultural "product" is taken away from the Indigenous community'. 51 However, Agency and Legacy argues that cultural commodification should be considered a dual process wherein it is both an economic response to the global expansion of the service sector and a politically motivated expression of identity'. ${ }^{52}$

Inauthenticity plagues artefacts made for sale, including claims that 'local culture[s] are made inauthentic' through commodity production. ${ }^{53}$ Bunten argues that such views 'do not take in account the basic premise that cultural productions are not static entities, only 'pure' when untouched by outside influences. ${ }^{54}$ Garth's and Estelle's experiences and understandings of their own boomerang production is based on a strong sense of cultural continuation and connection. Anthropologists know that ethnicity is a 'social construction' but our understanding of ethnicity is also less of what someone has and more of what someone does. ${ }^{55}$

49 Henry, Otto and Wood, 'Ethnographic Artifacts and Value Transformations', 35.

50 Henry, Otto and Wood, 'Ethnographic Artifacts and Value Transformations', 39.

51 Ruhanen and Whitford, 'Racism as an Inhibitor', 1731.

52 Bunten, 'Sharing Culture or Selling Out?', 381.

53 Bunten, 'Sharing Culture or Selling Out?', 384, quoting Greenwood, 'Culture by the Pound'.

54 Bunten, 'Sharing Culture or Selling Out?', 384.

55 Stronza, 'Through a New Mirror', 245. 
This article has a large focus on boomerangs because, unlike shadow boxes or pottery, boomerangs for tourist sale are rarely considered for their artistic value or their cultural importance. The legacy of the tourism industry still hangs heavy over boomerangs with their affordability and mass production often preventing an understanding of their cultural value. Boomerangs do have an economic benefit, having provided income for Aboriginal artists for decades. Houses, cars, educational opportunities and retirement have all been funded by the making and selling of boomerangs. There is also an incredible cultural significance to boomerang production in Queensland. Aboriginal people who were removed from their country and their families reconnect to their ancestral ways through the making of boomerangs. Through market engagements, Aboriginal people are able to educate visitors about their ancient cultures and contemporary ways of being. Boomerangs are decorated with stories of hunting and gathering, of basket making and dancing, of special places, family designs and regional animals. These stories and ways of being are communicated through boomerangs. All of this is possible through the making and selling of boomerangs and Agency and Legacy recognises their cultural and historical value.

The idea of the tainted object is the problem I have addressed in this article. It creates a lens through which to look at the objects passing through QAC. The idea of the tainted implies the idea of the untainted. Instead of asking where the taint comes from, it is just as important to ask where the untainted comes from. Untainted objects are true to an expected form - a philosophical idea of a true boomerang or spear thrower. The untainted is located in the object. The tainted is located firmly in the maker. As John Conroy has said, museums and galleries did not want to even look at objects passing through QAC..$^{56}$ The taint was with makers working through QAC's doors. Boomerangs were being collected but not through QAC. Placing the taint solely on QAC still undermines the artists who were engaged in economic outcomes that helped them and their families.

An Indigenous person regardless of their background has a story. The true authenticity question should pertain to artistic expression rather than Indigeneity: it is not the degree to which an artist's Indigeneity conforms with expectations but how the artist transforms their story into artworks and artefacts. That is the value and that is the authenticity of artists working for QAC. That is story that has been missing and the story Agency and Legacy tells. Instead of casting their ethnographic gaze at these forms of material culture, anthropologists should listen to the contemporary stories their makers are telling. A more solid understanding of the historical underpinnings of the makers, the government policies manipulating their modes of production and how they navigated structural limitations in the reception of their works needs to

56 Personal communication, 5 October 2019 
inform how we view these artefacts. The value of a boomerang needs to incorporate these aspects so that we can recognise the object's forms of economic, cultural and social agency it encompasses.

\section{Acknowledgements}

I would like to extend my heartfelt appreciation to Michael Aird and Mandana Mapar for their partnership and expertise in the creation of Agency and Legacy. Their passion and commitment to exploring the QAC story was and continues to be invaluable. A warm thank you to Garth Murgha, Estelle Tranby and John Conroy for sharing their personal experiences and perspectives. I look forward to continuing to work with you in the future. A final thank you goes to the two anonymous reviewers who really helped my thinking about these histories. Travel funding for this research was provided by the UQ Anthropology Museum, while time for the write up was funded by the Berndt Foundation.

\section{References}

\section{Archival source}

Queensland State Archives. Correspondence, Aboriginal and Torres Strait Islander.

\section{Other sources}

Aird, Michael. Brisbane Blacks. Southport, Qld: Keeaira Press, 2001.

Allen, Lindy. 'A History of Collecting Indigenous Artefacts in North Queensland'. In Story Place: Indigenous Art of Cape York and the Rainforest, edited by Queensland Art Gallery, 30-43. South Brisbane: Queensland Art Gallery, 2003.

Allen, Lindy. 'Tons and Tons of Valuable Material: The Donald Thompson Collection'. In The Makers and Making of Indigenous Australian Museum Collections, edited by Nicolas Peterson, Lindy Allen and Louise Hamby, 387-418. Melbourne: Melbourne University Press, 2008.

Anderson, Sally. 'The Aboriginal Art Industry in Cairns, Queensland: An Ethnographic Study'. PhD diss., School of Archaeology and Anthropology, The Australian National University, Canberra.

Best, Anne. 'The Aboriginal Material Culture of the Wellesley Islands and Adjacent Mainland Coast, Gulf of Carpentaria: Social and Environmental Factors Affecting Variations in Style.' Queensland Archaeological Research 15 (2012): 1-46. doi.org/10.25120/qar. 15.2012.232. 
Bunten, Alexis Celeste. 'Sharing Culture or Selling Out? Developing the Commodified Persona in the Heritage Industry'. American Ethnologist 35, no. 3 (2008): 380-95. doi.org/ 10.1111/j.1548-1425.2008.00041.x.

Burton, H. K. The Re-Establishment of the Indians in Their Pueblo Life through the Revival of Their Traditional Crafts: A Study in Home Extension Education. New York: Teachers College, Columbia University, 1936.

Demozay, Marion. Gatherings II: Contemporary Aboriginal and Torres Strait Islander Art from Queensland, Australia. Southport, Qld: Keeaira Press, 2006.

Graburn, Nelson, ed. Ethnic and Tourist Arts: Cultural Expressions of the Fourth World. Berkeley: University of California Press, 1979.

Greenwood, Davydd J. 'Culture by the Pound: An Anthropological Perspective on Tourism as Cultural Commodification'. In Hosts and Guests: The Anthropology of Tourism, edited by Valene L. Smith, 169-86. Philadelphia: University of Pennsylvania Press, 1989. doi.org/ 10.9783/9780812208016.169.

Harper, Sam. 'Engraved Material Culture in a Fluid Landscape: Looking at Designs on Shields, Spearthrowers and Boomerangs in the Port Hedland Rock Art Repertoire'. The Artefact, no. 38 (2015): 41-52.

Henry, Rosita, Ton Otto and Michael Wood. 'Ethnographic Artifacts and Value Transformations'. HAU: Journal of Ethnographic Theory 3, no. 2 (2013): 33-51. doi.org/ 10.14318/hau3.2.004.

Jones, Philip. Boomerang: Behind an Australian Icon. Kent Town, SA: Wakefield Press, 1996.

Jones, Philip. 'The "Idea Behind the Artefact": Norman Tindale's Early Years as a Salvage Ethnographer'. In The Makers and Making of Indigenous Australian Museum Collections, edited by Nicolas Peterson, Lindy Allen and Louise Hamby, 315-54. Melbourne: Melbourne University Press, 2008.

Jones, Tod, Jessica Booth and Tim Acker. 'The Changing Business of Aboriginal and Torres Strait Islander Art: Markets, Audiences, Artists, and the Large Art Fairs'. The Journal of Arts Management, Law, and Society 46, no. 3 (2016): 107-21. doi.org/10.1080/106329 21.2016.1182953.

Kleinert, Sylvia and Margo Neal. The Oxford Companion to Aboriginal Art and Culture. Oxford: Oxford University Press, 2000.

Morphy, Howard. Becoming Art: Exploring Cross-Cultural Categories. Sydney: UNSW Press, 2008.

National Museum of Australia. Old Masters: Australia's Great Bark Artists. Canberra: National Museum of Australia, 2013. 
Perusco, Anne. 'Only Sticks and Bark: Ursula McConnel - Her Collecting and Collection'. In The Makers and Making of Indigenous Australian Museum Collections, edited by Nicolas Peterson, Lindy Allen and Louise Hamby, 419-45. Melbourne: Melbourne University Press, 2008.

Potter, K. K. 'James Houston, Armchair Tourism, and the Marketing of Inuit Art'. In Native American Art in the Twentieth Century: Makers, Meanings, Histories, edited by W Jackson Rushing, III, 39-56. New York: Routledge, 1999.

Ruhanen, Lisa and Michelle Whitford. 'Cultural Heritage and Indigenous Tourism'. Journal of Heritage Tourism 14, no. 3 (2019): 179-91. doi.org/10.1080/1743873X.2019.1581788.

Ruhanen, Lisa and Michelle Whitford. 'Racism as an Inhibitor to the Organisational Legitimacy of Indigenous Tourism Businesses in Australia.' Current Issues in Tourism 21, no. 15 (2018): 1728-42. doi.org/10.1080/13683500.2016.1225698.

Ruhanen, Lisa, Michelle Whitford and Char-lee McLennen. 'Indigenous Tourism in Australia: Time for a Reality Check'. Tourism Management 48 (2015): 73-83. doi.org/ 10.1016/j.tourman.2014.10.017.

Ryan, Judith. Spirit in the Land: Bark Paintings from Arnhem Land. Melbourne: National Gallery of Victoria, 1990.

Stolte, Gretchen. Aboriginaland Torres Strait Islander Art: AnAnthropology ofIdentity Production in Far North Queensland. London: Routledge, 2020. doi.org/10.4324/9781003084365.

Stronza, Amanda. 'Through a New Mirror: Reflections on Tourism and Identity in the Amazon.' Human Organization 67, no. 3 (2008): 244-57. doi.org/10.17730/humo.67.3. a556044720353823. 
This text is taken from Aboriginal History, Volume 44, 2020, edited by Crystal McKinnon and Ben Silverstein, published 2021 by ANU Press, The Australian National University, Canberra, Australia.

doi.org/10.22459/AH.44.2020.05 